\title{
Avaliação qualitativa do ensino de Arte no Ensino Médio ${ }^{1}$
}

\section{The qualitative evaluation of Art Education in High School}

Tiago Cruvinel ${ }^{2}$ 


\section{Resumo}

Este artigo propõe a elaboração de objetivos de aprendizagem para o processo de avaliação qualitativa do ensino de Arte no Ensino Médio. $O$ estudo apresenta critérios para analisar a efetividade do ensino de Arte. Entende-se por efetivo, o ensino de Arte que, além de propiciar o conhecimento dos recursos materiais, procedimentos e elementos de cada linguagem (Artes Visuais, Dança, Teatro e Música), garanta as aprendizagens necessárias para a leitura da realidade, o enfrentamento dos novos desafios da contemporaneidade (sociais, econômicos e ambientais) e a tomada de decisões éticas e fundamentadas, conforme estabelecido pela BNCC do Ensino Médio. A partir das categorias elaboradas por determinados estudantes e da análise crítica da BNCC (Base Nacional Comum Curricular), realizou-se um cruzamento dos dados e se propôs objetivos de aprendizagem que levam em consideração - para a avaliação qualitativa - dois campos: o da transformação dos estudantes e o da didática.

Palavras-chave: Ensino de arte; objetivos de aprendizagem; avaliação; BNCC

\section{Abstract}

This article proposes to elaborate learning objectives in the qualitative evaluation for the process of the education of Art in High School. The study presents criteria to analyze the effectiveness of Art teaching. It is understood by effective, the teaching of Art that, in addition to providing knowledge of the material resources, procedures and elements of each artistic segment (Visual Arts, Dance, Theater and Music), it guarantees the necessary learning for the reading of the reality, the confrontation of the new challenges of contemporaneity (social, economic and environmental) and the making of ethical and reasoned decisions, as established by High School BNCC. Based on categories elaborated by certain students and the critical analysis of the third version of the BNCC document, a cross-checking of the data was carried out and learning objectives were proposed taking into account - for the qualitative evaluation - two prospects: the transformation of the students and of didactics.

Keywords: Art education; learning objectives; evaluation; BNCC

\footnotetext{
1 Este artigo é resultado do Pós-Doutorado realizado no PPG Artes EBA/UFMG, no período de março de 2018 a fevereiro de 2019 , sob a supervisão da professora Dra. Mariana Lima Muniz.

2 Professor doutor, do Instituto Federal de Minas Gerais (IFMG). tiago.brito.cruvinel@gmail.com
} 
Ao buscar mapear o ensino de Arte no Instituto Federal de Minas Gerais- IFMG (Betim, Ouro Branco e Conselheiro Lafaiete), como parte das minhas investigações do Pós-Doutorado, percebi que há uma imensa dificuldade em classificarmos se uma determinada unidade escolar possui ou não um ensino efetivo de Arte, independentemente das condições de trabalho dos professores.

A maior dificuldade nessa classificação está na falta de definição dos objetivos/ critérios claros e dos propósitos da Arte no Ensino Médio (CRUVINEL, 2017). A partir deles se poderia, por exemplo, observar o trabalho desenvolvido em uma determinada escola e ter, ou criar, os instrumentos necessários para compreender o trabalho ali desenvolvido.

O problema de não se ter critérios claros, para esse tipo de análise, é que essa ausência não nos permite propor ações efetivas, como políticas públicas, para melhorar o ensino que ali ocorre e mapear, de forma factual, principalmente o ensino de Arte nas escolas públicas.

Vamos supor que os estudantes não tiveram nenhum contato com obras visuais, espetáculos de teatro, dança ou música, teria aquela unidade escolar um ensino de Arte efetivo? E se, por outro lado, esses mesmos estudantes do Ensino Médio tivessem optado por desenvolver, durante todo ano letivo, apenas um espetáculo teatral, teria ainda essa unidade escolar um ensino de Arte efetivo?

A partir da minha experiência como docente, sei que, em muitos casos, é preciso negociar com a realidade, e o ensino efetivo de qualquer disciplina estará relacionado à boa vontade dos educadores, a partir daquilo que é possível fazer no momento presente - dadas as condições de trabalho. Mas, ainda assim, é importante refletirmos sobre os critérios para a avaliação qualitativa da Arte nas escolas, mesmo que, em muitos casos, a realidade esteja distante daquilo que se almeja como o ideal de ensino.

Buscar critérios objetivos para compreender o ensino de Arte não é dizer que uma determinada metodologia de ensino é melhor do que a outra, no sentido de afirmar, por exemplo, que um ensino só é efetivo se os jogos teatrais de Viola Spolin ou o Drama como método de ensino (CABRAL, 2006) forem aplicados. Também não é dizer que esses objetivos de aprendizagem são sinônimos dos conteúdos que devem ser trabalhados em sala de aula. Afinal, não se pode dizer que o conteúdo "Teatro gestual", por exemplo, é um objetivo educacional, pois, se assim o fizermos, estaremos reduzindo o trabalho do professor ou da professora à esfera conteudista e afirmando que um bom professor(a) só é aquele ou aquela que ensina os fundamentos do "Teatro gestual".

Dessa maneira, o ponto chave é: não é possível definir o que seria um ensino de Arte efetivo ou fugimos dessa problemática pelo receio de cairmos no lugar das Ciências Exatas, por exemplo? Ciências essas que define um ensino efetivo, na maioria dos casos, por meio dos resultados positivos que os estudantes adquiriram em exames nacionais ou internacionais, como as Olimpíadas de Matemática. Isto é, uma vez que não temos esses exames na área de Arte, não poderíamos propor outro tipo de análise que leve em conta os contextos socioculturais em que os estudantes estão envolvidos? 


\section{A transformação qualitativa}

Antes mesmo de adentrar nas questões específicas que envolvem este artigo, é fundamental compreender o que escrevem José Gimeno Sacristán e Ángel Pérez Gómez, na introdução do livro La enseñanza: su teoría y su práctica (2008). Para os autores, a educação, em regra, e, neste caso, o ensino de Arte, precisa passar por uma transformação qualitativa, de modo que essa melhora da qualidade do ensino deverá percorrer, impreterivelmente, a transformação do pensamento, das atitudes e do comportamento dos professores.

Ao buscar identificar determinados critérios como objetivos de aprendizagem para a compreensão do ensino de Arte, deparamo-nos com um receio bastante real e preocupante: os moldes do sistema tecnicista.

Sacristán \& Goméz (2008) relatam que foi a partir dos trabalhos, no ano de 1956, de Benjamin S. Bloom [1913-1999], psicólogo educacional, que se elaborou uma taxonomia de objetivos para a educação. Segundo eles, essa taxonomia foi criada justamente pelo desejo de que fossem elaboradas provas mais precisas, exames mais técnicos, no sentido de que a eficiência do ensino seria medida pelos resultados obtidos na prova, como um reflexo fiel daquela unidade escolar.

Esse modelo tecnicista tinha uma metodologia muito bem definida e contava com objetivos precisos. Criou-se, portanto, "taxonomía jerárquica de tipos de aprendizaje, que después se convierten en tipos precisos de objetivos" [estes que eram avaliados por meios de provas]" (Sacristán \& Goméz, 2008, p. 255). Consequentemente, apresentou-se, segundo Sacristán \& Goméz (2008), uma roupagem "científica" a um currículo muito conservador.

Dessa forma, evidencio que é possível refletir sobre os objetivos de aprendizagem no ensino de Arte, sem cairmos na perspectiva tecnicista de um currículo conservador ou da taxonomia de Benjamin S. Bloom. Essa empreitada pode ser feita pelas razões apresentadas por Elliot W. Einser [1933-2014], quando ele questionou se os objetivos de aprendizagem servem como ajuda ou como obstáculos aos professores.

Para Einser (2008), de maneira geral, os objetivos são responsáveis pela elaboração de metas que se alinham ao currículo, facilitam na organização e na seleção dos conteúdos a serem lecionados e tornam possível avaliar os resultados de um currículo. Além disso, esses objetivos de aprendizagem podem auxiliar na avaliação qualitativa do componente curricular a partir do trabalho desenvolvido pelos professores de Arte.

Todavia, Einser (2008) complementa que esses objetivos podem tanto complicar quanto ajudar no processo de ensino e de aprendizagem. Segundo o pesquisador, eles nos atrapalham se forem vistos como dogmatizadores. Nesse sentido, essa discussão é bastante pertinente para o contexto brasileiro atual, se levarmos em consideração a recente mudança do Ensino Médio e a construção da Base Nacional Comum Curricular (BNCC). 


\section{Análise crítica da BNCC}

Durante a elaboração desta pesquisa e da análise da BNCC do Ensino Médio, não se esperava a renúncia do Presidente da Comissão Bicameral do CNE (ConseIho Nacional da Educação), Cesar Callegari, encarregado da Base Nacional Comum Curricular. Em sua carta de renúncia, Callegari fez diversas críticas, dentre a mais importante, está que não é possível "separar a discussão da BNCC da discussão da Lei no 13405 [2017] que teve origem em Medida Provisória do Presidente da República e estabeleceu os fundamentos do que chamam de "Reforma do Ensino Médio".

E complementa:

Portanto, desde o início, a BNCC foi imaginada para ser uma base para a equidade que ajudasse a elevar a qualidade da educação brasileira. Contudo, na contramão de tudo o que se pensou, a nova Lei do Ensino Médio estabelece que esses direitos serão reduzidos e limitados ao que puder ser desenvolvido em, no máximo, 1800 horas. Ou seja: apenas ao que couber em cerca de $60 \%$ da atual carga horária das escolas. Pergunta-se, então: o que vai ficar de fora? Quanto de língua portuguesa, de biologia, de filosofia, de matemática, química, história, geografia, física, arte, sociologia, língua estrangeira, educação física? Quantos conhecimentos serão excluídos do campo dos direitos e obrigações e abandonados no terreno das incertezas, dependendo de condições, em geral precárias, e das vontades por vezes poucas? E mais: uma Base reduzida pode levar ao estreitamento do escopo das avaliações e exames nacionais que já consolidaram um papel marcante no nosso sistema educacional. E então? Exames como o ENEM também serão reduzidos, a indicar que, agora, muito menos será garantido e exigido? Incapazes de oferecer educação de qualidade, baixam a régua, rebaixam o horizonte. Essa, a mensagem que se passa para a sociedade ${ }^{3}$.

Com essa carta, vemos que os problemas - a que se refere Callegari - estão atrelados mais a lei que reformulou o Ensino Médio, do que a existência de uma Base Nacional. Ao ser questionado pela revista Carta Capital, sobre a importância da BNCC, Callegari diz que:

Nós sempre pensamos a ideia de uma Base, desde antes mesmo do Plano Nacional de Educação, como uma expressão dos direitos de aprendizagem. Ainda na condição de secretário nacional da educação básica, eu fui o primeiro a apresentar para o CNE uma proposta de Base Nacional relativa ao ciclo de alfabetização, o que acabou não prosperando. Mas enfim, eu acredito nisso, que o direito é uma construção social e precisa ser sempre enunciado, não basta apenas dizer que a criança ou o jovem tem direito à educação de qualidade. É preciso dizer o que significa qualidade em educação, quais são os aprendizados que essas crianças têm direito e os deveres dos governos, escolas e professores em relação a concretização deles ${ }^{4}$.

Além das críticas apontadas por Callegari, um dos pontos discutidos por profissionais da área de Arte é que a Base Nacional Comum Curricular, que criou as competências gerais da Educação Básica e as competências específicas para cada itinerário formativo, em nível nacional, pode cair na esfera do dogmatismo, tirando do professor ou

\footnotetext{
3 Disponível em: http://www.epsjv.fiocruz.br/carta-aos-conselheiros-do-conselho-nacional-de-educacao-cesar-callegari-renuncia-a-presidencia-da. Acesso: 6 nov. 2018.

4 Disponível em: http://www.cartaeducacao.com.br/entrevistas/reforma-do-ensino-medio-vai-acirrar-desigualdades-educacionais-e-sociais-diz-callegari/. Acesso: 6 nov. 2018.
} 
da professora e/ou da comunidade escolar a autonomia para definir seus próprios objetivos de aprendizagem.

Carminda André (2017), ao publicar seu parecer, que auxiliou os especialistas da área de Teatro na escrita da primeira versão da BNCC, diz que "a institucionalização do texto da BNCC, tal como está, [tem a tendência de] desautorizar o grupo de professores a inventar seus modos de fazer e de articular os conhecimentos a partir de suas formações, do entorno e de seus desejos coletivos" (2017, p. 18).

Na apresentação da BNCC homologada enuncia-se que:

A Base Nacional Comum Curricular (BNCC) é um documento de caráter normativo que define o conjunto orgânico e progressivo de aprendizagens essenciais que todos os alunos devem desenvolver ao longo das etapas e modalidades da Educação Básica, de modo a que tenham assegurados seus direitos de aprendizagem e desenvolvimento, em conformidade com o que preceitua o Plano Nacional de Educação (PNE) (BNCC, 2018, p.7, grifo dos autores).

Ademais, o texto da Base explicita que a flexibilidade da organização curricular - que possibilitará a opção de escolha dos estudantes, por itinerário formativo - deve ser tomada como princípio obrigatório. "Para que a organização curricular a ser adotada [...] - responda aos diferentes contextos e condições dos sistemas, das redes e das escolas de todo o País, é fundamental que a flexibilidade seja tomada como princípio obrigatório" (BNCC, 2018, p.479). Na BNCC, esse pensamento é concluído com a citação do relatório do Conselho Nacional de Educação e da Câmara de Educação Básica sobre as Diretrizes Curriculares Nacionais, de 2011, em que consta que é necessário: "romper com a centralidade das disciplinas nos currículos e substituí-las por aspectos mais globalizadores e que abranjam a complexidade das relações existentes entre os ramos da ciência no mundo real" (CNE/ CEB nำ/2011, p.43).

É importante enfatizar que esse relatório foi realizado em 2011, bem antes do processo de impeachment (2016) da Presidente Dilma Rousseff. Isto quer dizer que, tanto a ideia de construção da BNCC, quanto do rompimento das disciplinas, como centrais aos currículos, não se deu por iniciativa apenas do governo Michel Temer que homologou a BNCC.

Concordando com os autores citados, vejo que a autonomia, a que se refere a BNCC, e o poder de escolha dos estudantes são limitados. No que tange à escola, a ela lhe é dito que a flexibilidade deverá ser vista como um princípio obrigatório, não havendo muito espaço para a manutenção do currículo por disciplinas, caso a comunidade escolar assim preferir. E, ao estudante, coloca-se a falsa impressão de que ele irá escolher seu eixo formativo. A ideia é astuciosa, pois é sabido que muitas escolas não conseguirão ofertar mais do que um ou dois itinerários formativos, por conta do contexto em que estão inseridas e de suas condições estruturais. Nesse caso, os estudantes deverão se deslocar para outras cidades/regiões em busca do eixo formativo que condiga mais com o seu perfil acadêmico.

É imprescindível esclarecer também que a autonomia à qual Carminda se refere, tão importante e fundamental para o processo de ensino e de aprendizagem dos professores, em nenhuma ocasião pode se refletir na falta de organização e de pla- 
nejamento das aulas, visto que, a partir da minha própria experiência como docente, entendo que a autonomia não pode nos acomodar.

Outro aspecto analisado por Carminda André foi que as Artes sejam apresentadas como área de conhecimento e que se disponibilize aos professores conceitos e pedagogias em artes [citando os seguintes exemplos]: "estudos de pedagogia do teatro, pedagogias da performance, modos de aprendizagens indígenas e afrodescendentes [...], eliminando o formato objetivos-conteúdo que contraria o que se pode entender por 'base curricular'" (André, 2017, p.13-14).

No caso da Arte, na versão final da BNCC, ela não foi apresentada como área específica de conhecimento, mas como componente curricular da área de Linguagens e suas Tecnologias. Já a Lei de Diretrizes e Bases (LDB), coloca que "O ensino da arte, especialmente em suas expressões regionais, constituirá componente curricular obrigatório da educação básica (Redação dada pela Lei no 13.415, de 2017)" (Brasil, 1996, grifo do autor). Em vista disso, como a LDB é a lei maior que rege a Educação Brasileira, não se poderá excluir, em tese, a Arte como componente obrigatório da Educação Básica.

Em relação à apresentação da Arte como área específica de conhecimento, essa foi, inclusive, uma luta que, infelizmente, perdemos quando estivemos presentes no Seminário Arte na Escola, realizado pelo Conselho Nacional de Educação, nos dias 22 e 23 de agosto de 2018, em Brasília, em parceria com o Instituto Arte na Escola.

No primeiro momento, os especialistas de cada área Teatro, Artes Visuais, Dança e Música foram convidados a revisarem a segunda versão do texto "Pela obrigatoriedade do ensino de Artes no Ensino Médio - \#movimentoartenaescola ". O texto propunha, em linhas gerais, retirar a Arte da área de Linguagens e suas Tecnologias (Língua Portuguesa, Língua Inglesa e Educação Física), entendendo que essa é uma área de conhecimento específica. Nesse sentido, foi proposto a criação de mais um eixo formativo no Ensino Médio: o eixo Arte e suas Tecnologias.

Havendo esse novo eixo, os especialistas tiveram que pensar quais seriam as habilidades e as competências específicas dele. Como representante da ABRACE (Associação Brasileira de Pesquisa e Pós-Graduação em Artes Cênicas) e vice-coordenador do GT de Pedagogia das Artes Cênicas (Biênio 2017-2018), da área de Teatro, meu papel foi analisar as habilidades da BNCC do Ensino Fundamental, que já haviam sido homologadas, e pensar o que poderíamos ter no Ensino Médio. Infelizmente, como dito, não conseguimos inserir a arte em seu eixo específico.

Portanto, exemplifico, em linhas gerais, como a BNCC define a área de Linguagens no Ensino Fundamental atualmente e, consequentemente, no Ensino Médio. No Ensino Fundamental a área

está centrada no conhecimento, na compreensão, na exploração, na análise e na utilização das diferentes linguagens (visuais, sonoras, verbais, corporais), visando estabelecer um repertório diversificado sobre as práticas de linguagem e desenvolver o senso estético e a comunicação com o uso das tecnologias digitais. (BNCC, 2018, p.471) 
Já no Ensino Médio, por Linguagem, o documento entende as linguagens artísticas, corporais e verbais (oral ou visual, como Libras, e escrita), sendo elas objeto de estudo de diferentes componentes: Arte, Educação Física, Língua Inglesa e Língua Portuguesa. Na BNCC o foco da área de Linguagens e suas Tecnologias está

[...] na ampliação da autonomia, do protagonismo e da autoria nas práticas de diferentes linguagens; na identificação e na crítica aos diferentes usos das linguagens, explicitando seu poder no estabelecimento de relações; na apreciação e na participação em diversas manifestações artísticas e culturais; e no uso criativo das diversas mídias. (BNCC, 2018, p.471)

Os itinerários formativos - estratégicos para a flexibilização da organização curricular do Ensino Médio, pois possibilitam opções de escolha aos estudantes podem ser estruturados com foco em uma área do conhecimento, na formação técnica e profissional ou, também, na mobilização de competências e habilidades de diferentes áreas, compondo itinerários integrados, nos seguintes termos das DCNEM/2018:

I - linguagens e suas tecnologias: aprofundamento

de conhecimentos estruturantes para aplicação de diferentes linguagens em contextos sociais e de trabalho, estruturando arranjos curriculares que permitam estudos em línguas vernáculas, estrangeiras, clássicas e indígenas, Língua Brasileira de Sinais (LIBRAS), das artes, design, linguagens digitais, corporeidade, artes cênicas, roteiros, produções literárias, dentre outros, considerando o contexto local e as possibilidades de oferta pelos sistemas de ensino (BNCC, 2018, p.476)

Voltando à BNCC, dentre esses itinerários formativos, para garantir o protagonismo juvenil e a utilização de novas metodologias e procedimentos cognitivos, tanto a BNCC quanto o Conselho Nacional de Educação CNE, propuseram que os itinerários formativos sejam organizados em torno de um ou mais eixos estruturantes, sendo eles: investigação científica; processos criativos; mediação e intervenção sociocultural e empreendedorismo.

Não me deterei a todos esses eixos estruturantes, mas apresentarei apenas a definição daquilo que as Diretrizes Curriculares Nacionais entendem como processos criativos.

Processos criativos: supõe o uso e o aprofundamento do conhecimento científico na construção e criação de experimentos, modelos, protótipos para a criação de processos ou produtos que atendam a demandas pela resolução de problemas identificados na sociedade (Resolução CNE/CEB no 3/2018, Art. 12, § 2o).

É importante esclarecer que, embora seja importante termos um eixo, devidamente marcado na estrutura curricular, que diz respeito diretamente à área de Arte, esta visão de "processos criativos" relatada pelo CNE/CEB torna-se muito limitada. Os processos criativos, na área de Arte, têm sido vistos tanto na perspectiva da resolução de problemas a partir da realidade dada, quanto na criação de novos problemas a partir de novos terrenos. É por esse motivo que, Virgínia Kastrup (2007), prefere a utilização do termo invenção. Para ela, a definição de criatividade de Guilford, elaborada em 1956, estabeleceu a criatividade apenas como a solução de problemas já dados pela sociedade, fazendo, portanto, com que a liberdade de criação fosse restrita. Portanto, limitar o processo criativo apenas à resolução de problemas é deixar de lado o caráter transgressor e inovador da arte como propositora e transformadora da realidade. 
Além é claro que o melhor seria estarmos como eixo formativo específico: Arte e suas tecnologias, e não como uma metodologia do eixo estruturante Linguagens e suas tecnologias.

\section{As competências gerais na Educação Básica}

A fim de se discutir se é possível identificar critérios de aprendizagem para um ensino de Arte efetivo no Ensino Médio, proponho, neste momento, a continuação da análise da BNCC, e seus parâmetros legais, para, ao final deste texto, chegar a determinadas conclusões que possam apontar alguns critérios que nos auxiliariam na definição do que viria a ser um ensino de Arte efetivo no Ensino Médio.

De maneira ampla- pois meu objetivo aqui não será destrinchar todos os aspectos da BNCC, mas mostrar o que se relaciona, de maneira direta ou indiretamente, ao ensino de Arte -, a Base foi dividida em dez competências ${ }^{5}$ gerais na Educação Básica, que devem ser trabalhadas na Educação Infantil, no Ensino Fundamental e no Ensino Médio. Além disso, a BNCC estabeleceu, para cada área de conhecimento, competências específicas e relacionadas a elas são descritas as habilidades a ser desenvolvidas ao longo da etapa.

Dessas dez competências, percebe-se que existem ao menos cinco, que dizem respeito diretamente e/ou que tangenciam a área de Linguagens e suas Tecnologias. $\mathrm{Na} \mathrm{BNCC}$, o Ensino Médio foi reorganizado em quatro áreas do conhecimento, conforme determinou a LDB a partir da reforma do Ensino Médio.

O ensino por competência tem sido a marca "das novas políticas educativas, apoiadas, principalmente, pela UNESCO, a OCDE e os países envolvidos no tratado de Bolonha, visando tornar a expansão do conhecimento um motor do desenvolvimento econômico e social" (Chauvigné; Coulet, 2010, 2010, online) ${ }^{6}$. O que os pesquisadores Christian Chauvigné e Jean-Claude Coulet (2010) pontuam é que este tipo de ensino acaba por se tornar muito controverso, uma vez que muitos estudiosos entendem que - segundo eles - esse sistema de educação veio para servir aos interesses econômicos, em detrimento de uma formação mais aberta, crítica, humana e cidadã. De tal modo que este tipo de sistema reconhece o papel da educação no desenvolvimento econômico, mas se esquece do papel da educação na emancipação social (Chauvigné; Coulet, 2010).

Por outro lado, os pesquisadores enfatizam que frente a reestruturação dos setores produtivos, com a renovação e a criação de novas profissões, cada vez mais o estudante precisa aprender a tomar iniciativas, a se adaptar e a ser mais autônomo. Nesse sentido, Christian Chauvigné e Jean-Claude Coulet (2010) enfatizam que a aprendizagem pelo modelo padrão parece ser inoperante. Já o modelo por competências, concebido como uma organização cognitiva evolutiva, seria mais capaz de fornecer respostas comportamentais às expectativas educacionais relacionadas a esse contexto (Chauvigné; Coulet, 2010).

\footnotetext{
5 "Na BNCC, competência é definida como a mobilização de conhecimentos (conceitos e procedimentos), habilidades (práticas, cognitivas e socioemocionais), atitudes e valores para resolver demandas complexas da vida cotidiana, do pleno exercício da cidadania e do mundo do trabalho" (BNCC, 2018, p.8).

6 No original: «Elle est la marque des nouvelles politiques éducatives, soutenues par l'UNESCO, l'OCDE et les États engagés dans le processus de Bologne, visant à faire de la diffusion des savoirs un moteur du développement économique et social ». (Tradução nossa)
} 
Além disso, aos que defendem o ensino por competências, elas servem "apenas como um pretexto e um fio condutor para construir uma representação coerente do ofício do professor e de sua evolução" (Perrenoud, 2000, p.10).

Voltando às competências da BNCC, as cinco competências gerais, das dez, a que me refiro são:

1 - Valorizar e utilizar os conhecimentos historicamente construídos sobre o mundo físico, social, cultural e digital para entender e explicar a realidade, continuar aprendendo e colaborar para a construção de uma sociedade justa, democrática e inclusiva.

2 - Exercitar a curiosidade intelectual e recorrer à abordagem própria das ciências, incluindo a investigação, a reflexão, a análise crítica, a imaginação e a criatividade, para investigar causas, elaborar e testar hipóteses, formular e resolver problemas e criar soluções (inclusive tecnológicas) com base nos conhecimentos das diferentes áreas.

3 - Valorizar e fruir as diversas manifestações artísticas e culturais, das locais às mundiais, e também participar de práticas diversificadas da produção artístico-cultural.

4 - Utilizar diferentes linguagens - verbal (oral ou visual-motora, como Libras, e escrita), corporal, visual, sonora e digital -, bem como conhecimentos das linguagens artística, matemática e científica, para se expressar e partilhar informações, experiências, ideias e sentimentos em diferentes contextos e produzir sentidos que levem ao entendimento mútuo.

5 - Valorizar a diversidade de saberes e vivências culturais e apropriar-se de conhecimentos e experiências que lhe possibilitem entender as relações próprias do mundo do trabalho e fazer escolhas alinhadas ao exercício da cidadania e ao seu projeto de vida, com liberdade, autonomia, consciência crítica e responsabilidade.

Além dessas competências gerais, foram criadas competências específicas para cada itinerário formativo, as quais serão abordadas a seguir. Por ora, é importante entender como a BNCC, em outro trecho do documento, caracteriza o componente Arte. Para o documento:

A Arte, enquanto área do conhecimento humano, contribui para o desenvolvimento da autonomia reflexiva, criativa e expressiva dos estudantes, por meio da conexão entre o pensamento, a sensibilidade, a intuição e a ludicidade. Ela é, também, propulsora da ampliação do conhecimento do sujeito sobre si, o outro e o mundo compartilhado. É na aprendizagem, na pesquisa e no fazer artístico que as percepções e compreensões do mundo se ampliam e se interconectam, em uma perspectiva crítica, sensível e poética em relação à vida, que permite aos sujeitos estar abertos àspercepções e experiências, mediante a capacidade de imaginar e ressignificar os cotidianos e rotinas. (BNCC, 2018, p.482).

Antes dessa caracterização do componente, que me parece interessante e atualizada, a BNCC enfatiza a relevância do conhecimento dos jovens sobre a vida e as relações interpessoais que criam a partir dos contextos culturais e sociais em que estão inseridos. Nesta parte, a meu ver, também há um bom reconhecimento da Arte e do papel dela na construção da autonomia dos adolescentes, já que a BNCC destaca que a autonomia amplia as possibilidades de os jovens tanto entrarem na vida pública quanto produzirem cultura. Esta autonomia é criada a partir da autoria criativa e é definida como: 
Autoria de diversas produções que constituem as culturas juvenis manifestadas em músicas, danças, manifestações da cultura corporal, vídeos, marcas corporais, moda, rádioscomunitárias, redes de mídia da internet, gírias e demais produções e práticas socioculturais que combinam linguagens e diferentes modos de estar juntos. (BNCC, 2018, p. 481, grifo nosso).

É importante também, para a BNCC, que os estudantes possam relacionar essas manifestações artísticas com a contemporaneidade e "aprimorar sua capacidade de elaboração de análises em relação às produções estéticas que observam/vivenciam e criam" (BNCC, 2018, p.474). E, por fim, mas não nesta sequência, o documento trará a importância de os processos criativos incorporarem, aos seus estudos, tanto pesquisas e referências estéticas e poéticas, quanto referências sociais e políticas, visto que essa é uma maneira de chamar atenção do jovem para si e para o mundo (BNCC, 2018, p.474); gerando, com isso, "processos de transformação, de crescimento e de reelaboração de poéticas individuais e coletivas" (BNCC, 2018, p.474).

Além de apresentar os aspectos de cada componente da área de Linguagens e suas Tecnologias no Ensino Médio, a BNCC prioriza cinco campos de atuação social, sendo eles: campo da vida pessoal; campo das práticas de estudo e pesquisa; campo jornalístico-midiático; campo de atuação na vida pública; e campo artístico. Deter-me-ei a explicar apenas este último campo.

Por campo artístico entende-se que:

é o espaço de circulação das manifestações artísticas em geral, contribuindo para a construção da apreciação estética, significativa para a constituição de identidades, a vivência de processos criativos, o reconhecimento da diversidade e da multiculturalidade e a expressão de sentimentos e emoções. Possibilita aos estudantes, portanto, reconhecer, valorizar, fruir e produzir tais manifestações, com base em critérios estéticos e no exercício da sensibilidade. (BNCC, 2018, p.489)

Para a BNCC:

A consideração desses campos para a organização da área vai além de possibilitar aos estudantes vivências situadas das práticas de linguagens. Envolve conhecimentos e habilidades mais contextualizados e complexos, o que também permite romper barreiras disciplinares e vislumbrar outras formas de organização curricular (como laboratórios de comunicação e de mídias, clubes de leitura e de teatro, núcleos de criação artística e literária, oficinas culturais e desportivas etc.). Tais formas diversificadas de organização dos espaços e tempos escolares possibilitam uma flexibilização curricular tanto no que concerne às aprendizagens definidas na BNCC, já que escolhas são possíveis desde que contemplem os diferentes campos, como também às articulações da $\mathrm{BNCC}$ com os itinerários formativos. (BNCC, 2018, p.489)

É importante esclarecer que que os campos propostos pela BNCC não são fixos e podem transitar não só no componente Arte, mas em diferentes eixos formativos. 


\title{
Competências específicas da área de Linguagens e suas Tecnologias
}

\author{
Tudo isso posto, a partir dos campos de atuação e das competências gerais, \\ foram criadas competências específicas da área de Linguagens e suas Tecnologias e, \\ para cada competência específica, habilidades a serem alcançadas nessa etapa. \\ É oportuno enfatizar que a BNCC considera que:
}

esses pressupostos, e em articulação com as competências gerais da Educação Básica e com as da área de Linguagens do Ensino Fundamental, no Ensino Médio, a área de Linguagens e suas Tecnologias deve garantir aos estudantes o desenvolvimento de competências específicas. Três delas definem aprendizagens relativas às especificidades e aos saberes historicamente construídos acerca das Línguas, da Educação Física e da Arte (competências específicas 4, 5 e 6, respectivamente), enquanto as demais contemplam aprendizagens que atravessam os componentes da área. Relacionadas a cada uma delas, são indicadas, posteriormente, habilidades a ser alcançadas nessa etapa. (BNCC, 2018, p.489)

\section{Desse modo, as sete competências específicas são:}

1. Compreender o funcionamento das diferentes linguagens e práticas culturais (artísticas, corporais e verbais) e mobilizar esses conhecimentos na recepção e produção de discursos nos diferentes campos de atuação social e nas diversas mídias, para ampliar as formas de participação social, o entendimento e as possibilidades de explicação e interpretação crítica da realidade e para continuar aprendendo.

2. Compreender os processos identitários, conflitos e relações de poder que permeiam as práticas sociais de linguagem, respeitando as diversidades e a pluralidade de ideias e posições, e atuar socialmente com base em princípios e valores assentados na democracia, na igualdade e nos Direitos Humanos, exercitando o autoconhecimento, a empatia, o diálogo, a resolução de conflitos e a cooperação, e combatendo preconceitos de qualquer natureza.

3. Utilizar diferentes linguagens (artísticas, corporais e verbais) para exercer, com autonomia e colaboração, protagonismo e autoria na vida pessoal e coletiva, de forma crítica, criativa, ética e solidária, defendendo pontos de vista que respeitem o outro e promovam os Direitos Humanos, a consciência socioambiental e o consumo responsável, em âmbito local, regional e global.

4. Compreender as línguas como fenômeno (geo)político, histórico, cultural, social, variável, heterogêneo e sensível aos contextos de uso, reconhecendo suas variedades e vivenciando-as como formas de expressões identitárias, pessoais e coletivas, bem como agindo no enfrentamento de preconceitos de qualquer natureza.

5. Compreender os processos de produção e negociação de sentidos nas práticas corporais, reconhecendo-as e vivenciando-as como formas de expressão de valores e identidades, em uma perspectiva democrática e de respeito à diversidade.

6. Apreciar esteticamente as mais diversas produções artísticas e culturais, considerando suas características locais, regionais e globais, e mobilizar seus conhecimentos sobre as linguagens artísticas para dar significado e (re)construir produções autorais individuais e coletivas, exercendo protagonismo de maneira crítica e criativa, com respeito à diversidade de saberes, identidades e culturas.

7. Mobilizar práticas de linguagem no universo digital, considerando as dimensões técnicas, críticas, criativas, éticas e estéticas, para expandir as formas de produzir sentidos, de engajar-se em práticas autorais e coletivas, e de aprender a aprender nos campos da ciência, cultura, trabalho, informação e vida pessoal e coletiva. (BNCC 2018, p.490) 
Essas competências específicas já aparecem em diferentes pesquisas da área de Arte e se mostra, em certa medida, atualizada. O problema é que a BNCC não definiu competências específicas para cada componente escolar, assim como foi realizado com o Ensino Fundamental. É importante esclarecer que a ideia de competência é contrária à ideia de componente curricular. Este é um dos principais problemas da BNCC, usou-se o ensino por competências, mas, ao mesmo tempo, se manteve a ideia de componente curricular, causando a insegurança no sistema escolar. No caso das escolas brasileiras, poderá ocorrer, por exemplo, a sobrecarga de professores, não formados na área de Arte, como os de Língua Portuguesa - uma vez que essa disciplina, juntamente com a Matemática, são as únicas que aparecem como obrigatórias durante os três anos do Ensino Médio. Nesse sentido, poderíamos ter o professor generalista, aquele do Ensino fundamental I, na mesma perspectiva para o Ensino Médio.

\section{O que seria um ensino de Arte efetivo no Ensino Médio?}

Além da análise da BNCC, apresento alguns dados elaborados durante a minha pesquisa de Pós-Doutorado na EBA-UFMG. Nela, oito estudantes de iniciação científica (PIBIC-JR e PIBIC) mapearam também, junto a mim, o ensino de Arte no IFMG (Betim, Conselheiro Lafaiete e Ouro Branco). Estes estudantes do Ensino Médio e da Graduação foram agentes de campo e grupo de controle ao mesmo tempo. Deste modo, durante o processo de orientação utilizava os momentos de encontro para perceber o ponto de vista pessoal deles sobre o ensino de Arte. Portanto, eles se tornaram também grupo de controle.

O termo "agentes de campo", utilizado na pesquisa, surge dos estudos da jornalista Amanda Ripley (2009). Ao propor estudar os ambientes escolares da Finlândia, da Polônia, da Coreia do Sul e dos Estados Unidos, seu país de origem, Amanda Ripley se utilizou, como metodologia de pesquisa - além de entrevistas com profissionais da área, professores, coordenadores e representantes das leis locais -, de agentes de campo: adolescentes estadunidenses que, de maneira voluntária, elaboraram diários de bordo e participaram de encontros virtuais sobre suas experiências com os sistemas educacionais dos países nos quais estavam em imersão acadêmica. Desse modo, para Ripley (2009), quando os estudantes se tornam agentes de campo, é possível colher as informações do lado de dentro, ou seja, eles "poderiam ver e fazer coisas que eu jamais poderia. Por isso, recrutei uma equipe de jovens especialistas para me ajudar" (Ripley, 2009, p.23).

Antes de perguntar aos estudantes o que eles pensavam sobre o que seria um ensino de Arte efetivo, eles fizeram uma revisão de literatura a partir das seguintes temáticas: História do ensino de Arte no Brasil; criação das leis de Diretrizes e dos Parâmetros Curriculares Nacionais; Música, Teatro e Dança no Ensino de Arte; Diretrizes Curriculares da Educação Básica e a Base Nacional Comum Curricular. Cada estudante ficou responsável por uma ou por duas temáticas, e os resultados da pesquisa foram compartilhados entre todos, durante reuniões por Skype. 
A partir da revisão de literatura, eles puderam compreender melhor o que já foi proposto, em termos de legislação e de metodologias, para o ensino de Arte. Assim, após essa primeira etapa, solicitei aos estudantes que estabelecessem três categorias de análise de ensino do ensino de Arte, ou seja, o que eles julgavam que era importante para se ter um ensino de Arteefetivo.

Esses estudantes apresentaram vários critérios de análise que se interligam, direta ou indiretamente, às competências específicas da BNCC, apresentadas anteriormente. Para esses estudantes, um ensino de Arte efetivo no Ensino Médio é aquele em que o(a) professor(a):

- Desenvolve o potencial criativo, cognitivo e inter-relacional;

- Auxilia na interpretação de imagens e de músicas;

- Consegue captar a atenção dos estudantes;

- Cria modelos que fogem do padrão tradicional;

- Ensina Arte porque gosta;

- Tem conhecimento prévio das linguagens artísticas;

- Consegue ministrar aula mesmo com uma estrutura física limitada;

- Percebe que a Arte pode levar o estudante ao autoconhecimento;

- Propõe metodologias participativas;

- Preocupa-se mais com a qualidade do que com a quantidade de aulas.

De maneira geral, todos atribuíram aos professores a responsabilidade da eficiência ou da ineficiência do ensino de Arte. Não se falou da direção da escola, das políticas públicas ou da comunidade escolar. A centralidade da análise e das respostas foi no papel dos professores. Outrossim, vemos que o que ficou mais evidente foi a didática a ser mais bem trabalhada/construída em sala de aula: captar a atenção dos(as) alunos(as); criar novos modelos; propor metodologias participativas; preocupar-se mais com a qualidade; isto é, algo que não se vincula somente ao ensino de Arte. Todos esses pontos podem e devem ser (re)vistos nas demais áreas de conhecimento.

Outro ponto importante a ser destacado: "ministrar aula mesmo com a estrutura física limitada". Um dos grandes problemas enfrentados pelos professores de Arte é o espaço físico. A falta de estrutura sempre foi e sempre será uma "pedra em nossos sapatos". Sergio Farias (2009), há tempos, já nos mostrou que repetir o discurso da falta de estrutura e considerar os estudantes como casos perdidos na escola pública é "reforçar a condição de miséria e contribuir com a dominação" (2009, p.24). [Cabendo, a nós,] "conhecer as regras, identificar parceiros confiáveis nas diversas instâncias da organização social e entrar no jogo para enfrentar a problemática e promover a transformação desejada (2009, p.24, grifo do autor)". É aquela velha história: Fazer do limão uma limonada.

Deste modo, entrar no jogo e sair do jogo são metáforas interessantes para se pensar a prática pedagógica que precisa ser (re)vista em sala de aula. Os estudantes participantes desta pesquisa perceberam que é importante transpor a barreira da dificuldade e propor ações possíveis de serem executadas a partir daquilo que se tem na escola. 
Já em relação ao conteúdo, para além da didática dos professores, os estudantes enfatizaram que a Arte pode auxiliar no desenvolvimento do potencial não só criativo, mas cognitivo e inter-relacional. Inter-relacional no sentido de que a Arte é capaz de auxiliar no autoconhecimento dos estudantes e na melhor compreensão do mundo a sua volta. Esta definição aparece de forma evidente na BNCC.

O autoconhecimento não passa, necessariamente, pela perspectiva terapêutica ou psicanalítica. Fala-se aqui do lugar socrático-filosófico que coloca a Arte no campo da contestação, da mudança de ponto de vista. O objetivo da Arte Conceitual e Contemporânea, por exemplo, pode ser mudar o ponto de vista tanto da percepção do espectador confrontando a obra, quanto da mudança de percepção da sua própria vida -o que, obviamente, auxiliará no processo de autoconhecimento e de conhecimento do outro.

Destaco, ainda, que os estudantes enfatizaram a importância da disciplina no auxílio da interpretação de imagens e de músicas; e a importância de os professores de Arte terem conhecimento prévio das linguagens artísticas ensinadas em sala de aula. Volta-se, assim, à questão de que a polivalência pode causar uma enorme frustração aos estudantes. Ao se apresentar, na ementa da disciplina, que os estudantes terão conhecimentos das quatro linguagens, eles não querem ter apenas noções superficiais, eles querem a verticalização dos conhecimentos.

Retomo as três razões apresentadas por Einser (2008), na introdução do artigo, para propor os objetivos de aprendizagem no processo da avaliação qualitativa do ensino de Arte no Ensino Médio: a elaboração de metas; a facilitação na organização e na seleção dos conteúdos; e a avaliação qualitativa do componente Arte.

Como exemplo, para León Chancerel, o educador deve estar diante de dois objetivos gerais a serem cumpridos: proporcionar aos estudantes meios de expressão que sejam os mais completos possíveis e formar, ao mesmo tempo, "seu senso artístico, seu senso social e seu caráter" (Chancerel, 1936, p.6). Objetivos estes pensados em 1936, no contexto francês, que apresentam encaminhamentos interessantes em termos de construção de uma identidade ou de identidades comuns, em termos de sistema de ensino. Apenas diante desses objetivos propostos por Chancerel, os pesquisadores conseguiriam acompanhar uma determinada unidade escolar e perceber se o que está sendo trabalhado na escola caminha para conforme os objetivos propostos. Contudo, reconheço que esta definição de ensino efetivo pode ser datada e vem de um contexto diferente do brasileiro. Por isso, a importância de se refletir sobre o que é característico da nossa realidade.

Recupero, assim, a questão feita na introdução deste artigo: se os estudantes tivessem optado por desenvolver, durante todo o ano letivo, apenas um espetáculo teatral, teria ainda essa unidade escolar um ensino de Arte efetivo? Isto é, o que é necessário para se ter um ensino de Arte efetivo?

Se utilizarmos a BNCC, como princípio norteador, a partir das sete competências específicas que ela propõe, na área de Linguagens e suas Tecnologias, poderíamos dizer que sim, desde que, durante o processo de criação colaborativa, em sala de aula, o professor ou a professora viesse a propor os seguintes objetivos de aprendizagem. Tais objetivos visam criar uma ou mais identidades que sejam comuns ao ensino 
de Arte público brasileiro. É possível ainda constatar que, ao contrário do contexto francês, em 1936, proposto por Léon Chancerel, no Brasil, aumentou-se o número de pontos que precisam ser observados, dada a complexidade da nossa sociedade atual.

Os objetivos de aprendizagem podem ser analisados a partir de dois campos elaborados por esta pesquisa. Percebam que todos esses objetivos de aprendizagem foram retirados da BNCC e recolocados em dois campos: transformação dos estudantes e campo didático.

O primeiro, elaborado por esta pesquisa, o campo da transformação dos estudantes, terá a intenção de propiciar novas percepções e experiências que irão:

1. Auxiliar na construção da autonomia criativa e expressiva;

2. Ampliar o seu conhecimento de si, do outro e do mundo;

3. Melhorar as formas de participação social e de interpretação da realidade;

4. Compreender os processos identitários, os conflitos e as relações de poder que permeiam as práticas sociais;

5. Exercer, por meio de diferentes linguagens artísticas, com autonomia e colaboração, o protagonismo e a autoria na vida pessoal e coletiva, de forma crítica, criativa, ética e solidária;

6. Reconhecer e vivenciar formas de expressões identitárias, em uma perspectiva democrática e de respeito à diversidade, que levarão ao enfrentamento de preconceitos de qualquer natureza;

7. Dar significado e (re)construir produções autorais e coletivas (de modo crítico e criativo).

No segundo, o campo da didática, também elaborado pela pesquisa, os docentes deverão ministrar conteúdos que:

1. Façam o cruzamento de culturas e de saberes;

2. Aprimorem a capacidade dos estudantes de elaborar análises em relação às produções estéticas que observam/vivenciam e criam, em diálogo com a contemporaneidade;

3. Auxiliem na compreensão do funcionamento das diferentes linguagens e práticas artísticas, corporais e verbais;

4. Envolvam múltiplos aspectos na produção de sentidos nas práticas sociais da cultura corporal de movimentos;

5. Expandam as formas de produzir sentidos, na mobilização de práticas de linguagem no universo digital.

Essa preocupação em relação tanto ao campo da transformação dos estudantes quanto do campo da didática, dialoga bastante com o que que propõe a BNCC ao dizer que:

Para formar esses jovens como sujeitos críticos, criativos, autônomos e responsáveis, cabe às escolas de Ensino Médio proporcionar experiências e processos que lhes garantam as aprendizagens necessárias para a leitura da realidade, o enfrentamento dos novos desafios da contemporaneidade (sociais, econômicos e ambientais) e a tomada de decisões éticas e fundamentadas. (BNCC, 2018, p.461) 
Percebam que todos esses objetivos de aprendizagem foram retirados da BNCC e recolocados em dois campos: transformação dos estudantes e campo didático. Essa divisão, puramente instrutiva, tem o intuito de mostrar que o ensino de Arte efetivo deverá passar, necessariamente, pela transformação dos estudantes ou, ao menos, pela tentativa de transformação deles.

Transformação esta cuja centralidade não é terapêutica, mas que está na mudança de pontos de vista dos estudantes, por meio de novas percepções e experiências que trarão outras leituras da realidade e auxiliará os estudantes no enfrentamento dos novos desafios, sociais, econômicos e ambientais, além da tomada de decisões fundamentadas nos princípios éticos, conforme propõe a BNCC (2019). Não se trata aqui apenas de ensinar determinado conteúdo.

\section{Considerações finais}

Concluo que é possível ter subsídios para analisar se uma determinada unidade escolar tem ou não um ensino de Arte efetivo. Há uma enorme complexidade, presente em todas as áreas que trabalham no campo da subjetividade, mas vejo que é possível mensurar a qualidade do ensino de Arte, algo que ainda não foi, de fato, mensurado em nível nacional, a partir dos princípios e pressupostos que temos na documentação brasileira, como a BNCC, e realinhados neste artigo, por meio do campo da transformação do sujeito e do campo da didática. Ao fazermos esse alinhamento estaremos criando subsídios e tornando mais concreto o processo de avaliação qualitativa do ensino de Arte.

Tais pontos não excluem a subjetividade da área, os contextos socioculturais em que os estudantes estão inseridos e muito menos deixa de reconhecer o currículo oculto trabalhado em sala de aula, a partir da vivência de cada professor, de cada professora. Muito pelo contrário, eles evidenciam a importância das diversidades no processo didático e na transformação dos sujeitos.

Precisamos alinhar os nossos objetivos de aprendizagem na Arte do Ensino Médio, para que possamos, juntos, professores e estudantes, criar, posteriormente, os instrumentos de análise de cada ponto e mapear a qualidade do ensino no território brasileiro. Deste modo, será possível apresentarmos os dados que justifiquem o papel da Arte, a ampliação e a melhora nas estruturas da escola para o seu ensino, uma vez que ela tem como pilar transformar os sujeitos do ponto de vista ético, criativo e solidário, até como forma de resistência.

Talvez, se a população brasileira entender melhor os nossos objetivos de aprendizagem, possamos tê-la conosco na luta pela manutenção e pela permanência da Arte nas escolas. Caso contrário, a população poderá ver o componente como supérfluo no processo de ensino e de aprendizagem, em face, por exemplo, da avaliação do ENEM (Exame Nacional do Ensino Médio). 


\section{Referências}

ANDRÉ, Carminda Mendes. Dossiê: Arte na Educação Básica: conquistas, desmontes e políticas educacionais. Rascunhos - caminhos da pesquisa em Artes Cênicas, v. 4, p. 7-20, 2017.

BARBOSA, Ana Mae. A imagem no ensino da arte: anos 1980 e novos tempos. São Paulo: Perspectiva, 2012.

BRASIL. Ministério da Educação. Base Nacional Comum Curricular. Brasília, DF, 2018 (terceira versão). Disponível em: <http://basenacionalcomum.mec.gov.br/wp-content/ uploads/2018/04/BNCC_EnsinoMedio_embaixa_site.pdf>. Acesso em: 4 jun. 2018.

BRASIL. Lei de Diretrizes e Bases. Lei no 9.394/96, de 20 de dezembro de 1996.

BRASIL. Conselho Nacional de Educação (CNE). Parecer n. 5, de 4 de maio de 2011. Diretrizes Curriculares Nacionais para o Ensino Médio. Diário Oficial da União, Brasília, DF, 24 jan. 2012.

BRASIL. Conselho Nacional de Educação (CNE). Parecer n.3, de 8 de novembro de 2018. Atualização das Diretrizes Curriculares Nacionais para o Ensino Médio, observadas as alterações introduzidas na LDB pela Lei no 13.415/2017. Brasília, DF, 21 nov. 2018.

CABRAL, Beatriz. Drama como método de Ensino. São Paulo: Hucitec, 2006.

CHANCEREL, Léon; CHARBONNIER, Hélène; SAUSSOY; Anne-Marie. Jeux Dramatiquesdans l'éducation: Introduction a une Méthode. Paris: LibrairieThéatrale, 1936.

Christian Chauvigné et Jean-Claude Coulet, « L'approche par compétences : un nouveau paradigme pour la pédagogie universitaire ? ", Revue française de pédagogie, 172 | 2010, p.15-28. Disponível em: https://journals.openedition.org/rfp/2169. Acesso em 7 fev. 2019.

CRUVINEL, Tiago. A falta de compreensão dos objetivos e dos propósitos da disciplina Arte. Revista do Programa de Pós-Graduação em Artes da Escola De Belas Artes da UFMG, v. 7, p. 109-127, 2017.

EISNER, Elliot. Los objetivos educativos: ¿ Ayuda o estorbo?. In: SACRISTÁN, J; GÓMEZ, A (organizadores). La enseñanza: su teoría y su práctica. Espanha: AKAL, 2008.

FARIAS, Sérgio.Condições de trabalho com teatro na rede pública de ensino: sair de baixo ou entrar no jogo. Urdimento (UDESC), v. 1, p. 23-28, 2009.

KASTRUP, Virgínia. A invenção de si e do mundo. Belo Horizonte: Autêntica, 2007. 
PERRENOUD, Philippe. Dez novas competências para ensinar. Porto Alegre: Artmed, 2000.

RIPLEY, Amanda. As crianças mais inteligentes do mundo: e como elas chegaram lá. São Paulo: Três Estrelas, 2014.

SACRISTÁN, J; GÓMEZ, A (organizadores). La enseñanza: su teoría y su práctica. Espanha: AKAL, 2008.

Recebido em: 15/11/2018

Aprovado em: 08/01/2019 